Conclusions: The performance-based physical function measure ASPI was more sensitive to detect responders than the self-reported measure BASFI according to the ASAS20 response criteria in patients with axSpA after a high intensity exercise intervention. Our findings suggest that the performance-based physical function (ASPI) measure is preferable when evaluating physical function after exercise interventions with physical therapy.

Disclosure of Interest: None declared

DOI: 10.1136/annrheumdis-2018-eular.5133

\section{SAT0720-HPR MORE PRECISE MEASUREMENTS OF SPINAL MOBILITY WHEN ASSESSED WITH A SENSOR IN PATIENTS WITH AXIAL SPONDYLOARTHRITIS}

C. Fongen ${ }^{1}$, C.H. Franke ${ }^{2}$, D.M. Soldal ${ }^{2}$, V. Berre ${ }^{3}$, J.H. Relbe-Moe ${ }^{4}$, J. Hagfors ${ }^{4}$, A.T. Tveter ${ }^{1}$, N. Østerås ${ }^{1}$, K.B. Hagen ${ }^{1} .{ }^{1}$ Diakonhjemmet Hospital, Oslo; ${ }^{2}$ Hospital of Southern Norway, Kristiansand; ${ }^{3}$ Apertus, Bærum; ${ }^{4}$ Patient partners, Oslo, Norway

Background: Rotation of the spine is one of the principal movements of spinal motion. Cervical rotation (CR) is included in the assessment for monitoring axial spondyloarthritis (axSpA). Thoracolumbar rotation (TLR) is also known to be a valid measure for axSpA specific changes, but is seldom used due to lack of easy feasible measures. Goniometer or myrinometer (compass) is traditionally used to evaluate rotation. A sensor with excellent criterion validity and reliability for rotation in the range of motion from 10 to 120 degrees, that are able to detect changes of $\leq 1$ degree, has recently been developed ${ }^{1}$

Objectives: To examine the concurrent validity between the sensor and compass in CR and TLR and to evaluate the usability and satisfaction with the sensor. Methods: This study was part of the MOSKUS-study (Mobile mosculO Skeletal User Self-management). Patients with axSpA were included from two rheumatology outpatients' clinics and examined by experienced physiotherapists. CR and TRL were assessed three times with both the sensor and compass; mean score are used in the analyses. The measuring order was randomised. The sensor was considered gold standard. Group differences were assessed with paired sample ttest or Wilcoxon signed rank test, and agreement with Bland Altman plot. Time to conduct the test (instruction, conducting and note of results) was recorded for the 10 last included patients. Satisfaction was assessed both by the patients and assessors with numeric rating scale (NRS), (0-10, 10=highest satisfaction).

Results: A total of 60 patients with axial SpA and 2 assessors participated. Of the included patients $60 \%$ were male, median (min-max) age was $39^{20-73}$ years and $77 \%$ had radiographic axSpA. There were statistically significant differences in measure of rotation between the sensor and the compass of $3.7^{\circ}$ in $\mathrm{CR}$, $\mathrm{p}=0.01$ and $9.2^{\circ}$ in TLR, $\mathrm{p}<0.001$ (table 1). The Band Altman plots show that the compass systematically measured lower rotation than the sensor in both $\mathrm{CR}$ and TLR (figure). There was no difference in time used to conduct the measurements. Patients satisfaction in CR measured with the senor was mean (SD) 7.8 (2.4) and compass 6.7 (2.6), $\mathrm{p}<0.001$ and in TLR 7.8 (2.4) and $7.3(2.3), \mathrm{p}=0.08$ respectively. Assessors satisfaction in CR measured with the senor was 9.0 (1.2) and compass 5.6 (2.8) $\mathrm{p}<0.001$ and in TLR 8.1 (2.2) and 3.6 (2.2) $\mathrm{p}<0.001$, respectively.

Abstract SAT0720HPR - Table 1. Characteristics of rotation measures, agreement and time to conduct measurements

\begin{tabular}{llcccccc}
\hline Mobility & Measure & $\mathrm{n}$ & $\begin{array}{c}\text { Mean } \\
(\mathrm{SD})\end{array}$ & $\begin{array}{c}\text { Mean } \\
\text { difference } \\
(\mathrm{SD})\end{array}$ & p-value & $\begin{array}{c}\text { Time in sec, median } \\
(\mathrm{min}-\mathrm{max}), \mathrm{n}=10\end{array}$ & $\begin{array}{c}\mathrm{p}- \\
\text { value }\end{array}$ \\
\hline Cervical & Sensor & 59 & $\begin{array}{c}69.2 \\
(18.2)\end{array}$ & & & $96(44-216)$ & \\
& Compass & 59 & $\begin{array}{c}65.4 \\
(18.2)\end{array}$ & $3.7(10.0)$ & 0.01 & $96^{62-150}$ & 0.36 \\
& & & & $107(36-200)$ & \\
$\begin{array}{l}\text { Thoraco- } \\
\text { lumbar }\end{array}$ & Sensor & 56 & $\begin{array}{c}47.8 \\
(11.8)\end{array}$ & & & $86^{46-158}$ & 0.92 \\
& Compass & 56 & $\begin{array}{c}38.6 \\
(10.3)\end{array}$ & $9.2(9.5)$ & $<0.001$ & & \\
\hline
\end{tabular}

Conclusions: Measure of CR and TLR were significantly lower when measured with a traditional compass compared to a digital sensor. There were no difference in time use and both patients and assessors were more satisfied with the sensor. The results suggest that the sensor gives more precise measurements of rotation and allow a feasible way to assess TLR in daily clinical practise.

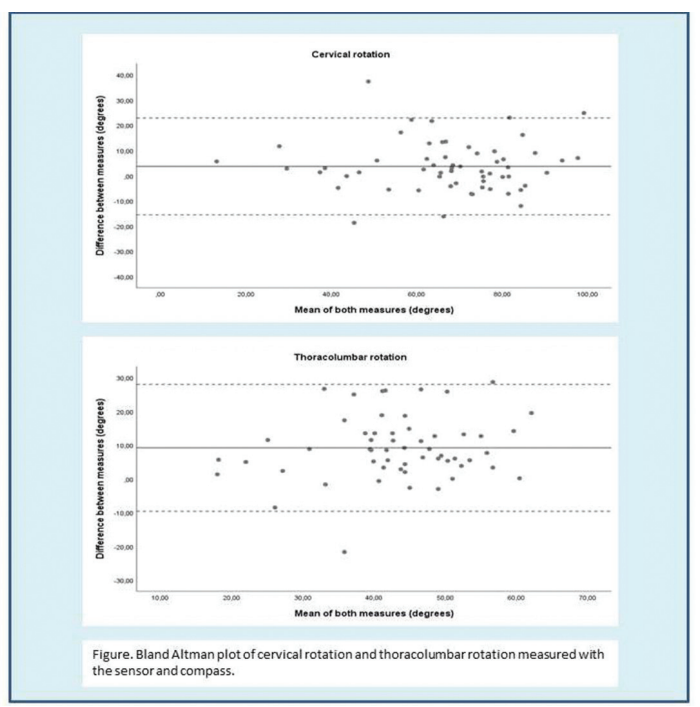

Abstract SAT0720HPR - Figure 1. Bland Altman plot of cervical rotation and thoracolumbar rotation measured with the sensor and compass.

\section{REFERENCE:}

[1] Fongen EULAR16-4002.

Disclosure of Interest: None declared DOI: 10.1136/annrheumdis-2018-eular.6185

\section{SAT0721-HPR IMPROVEMENT IN CLINICAL RESULTS BY ENHANCING ADHERENCE TO A HEALTHCARE MODEL IN RHEUMATOID ARTHRITIS}

D. Buitrago-Garcia ${ }^{1}$, L. Villarreal ${ }^{2}$, F. Rodriguez ${ }^{2}$, I. Mendez ${ }^{2}$, P. Santos-Moreno ${ }^{3}$ ${ }^{1}$ Epidemiology, SIIES; ${ }^{2}$ Health services; ${ }^{3}$ Rheumatology, Biomab, Center For Rheumatoid Arthritis, Bogota, Bogota, Colombia

Background: A Centre of Excellence ( $\mathrm{CoE}$ ) healthcare model aims to obtain a high quality results from the appropriate and minimal use of resources in rheumatoid arthritis (RA); Enhancing adherence of patients to healthcare model and treatment using a Treat to Target approach and patient education has demonstrated the improvement of patient conditions and clinical results. ${ }^{1}$

Objectives: To describe the adherence patterns to a centre of excellence model and clinical outcomes in patients with RA in a specialised centre. For this study researchers defined adherence as the attendance to an appointment with our healthcare team for more than three times during 12 months.

Methods: We reviewed the clinical records of patients with RA in a specialised centre during a 12 month period. We included socio demographic variables and the attendance to consultations to rheumatology, physiatry, physical therapy, occupational therapy, nutrition, and psychology consultations. Descriptive epidemiology was done, percentages and averages were calculated We analysed bivariate association with Pearson's $\mathrm{X}^{2}$.

Results: We included 5413 patients, where $83 \%$ were female and $17 \%$ were male; mean age was 59 years \pm 12 . Mean DAS28 of patients was $2.82 \pm 0.84$, where $46 \%$ of patients were on remission, $27 \%$ in low disease activity, $24 \%$ in moderate disease activity and $3 \%$ in severe disease activity. The specialty were the adherence was higher was in rheumatology $98 \%$, followed by physiatry $33 \%$, psychology $29 \%$, physical therapy $28 \%$, occupational therapy $20 \%$ and nutrition $13 \%$. In our study $47 \%$ of patients were considered as adherents; from all patients who were adherent $75 \%$ were in remission or low disease activity. When we compared disease activity with the attendance to all specialties there was statistical association between disease activity and the patients who attended to more than four visits.

Conclusions: Patients who attend satisfactory to a multidisciplinary healthcare approach team can achieve better results compared to those who doesn't attend to all medical specialties; thus it is relevant to implement patient education 
processes in order to create awareness about the importance and value of each medical specialty, mainly in patients with moderate or severe disease activity.

\section{REFERENCE:}

[1] Santos-Moreno P, Castaneda O, Garro B, Flores D, Sanchez G, Castro C From the model of integral attention to the creation of centers of excellence in rheumatoid arthritis. Clinical rheumatology 2015;(34 Suppl 1):S717.

Disclosure of Interest: None declared DOI: 10.1136/annrheumdis-2018-eular.6068

\section{SAT0722-HPR THE VALIDITY AND TEST-RETEST RELIABILITY OF THE TURKISH PATIENT SPECIFIC FUNCTIONAL SCALEIN CHRONIC NECK PAIN PATIENTS}

G. Yalcinkaya ${ }^{1}$, B. Kara ${ }^{1}$, M.N. Arda ${ }^{2} .{ }^{1}$ School of Physical Therapy and Rehabilitation; ${ }^{2}$ Department of Neurosurgery, Dokuz Eylül University, Izmir, Turkey

Background: Current clinical guidelines recommend to use both clinical and selfreported measurements for evaluation of chronic neck pain. Among the selfreported outcomes, Neck Disability Index (NDI) and Patient Specific Functional Scale (PSFS) are the most widely used and recommended instruments. ${ }^{1}$ Although, NDI was validated in Turkish language before, but no validation study related to the PSFS was detected in the literature.

Objectives: The purpose of our study was to determine the validity and reliability of PSFS which was not validated in Turkish language previously.

Methods: The PSFS has been translated into Turkish (PSFS-T) according to "translation-backward translation" method as recommended in the guidelines. Demographic data, PSFS-T, and NDI were recorded at the initial assessment. For the test-retest reliability analysis, the first 30 patients were called by phone. Intraclass correlation coefficient (ICC) was established for reliability analyses. The correlations between PSFS-T and NDI was examined for the validity analysis.

Results: The final form was completed by 110 chronic neck pain patients (F:77, $M: 33)$. The mean age of patients was $44 \pm 14$ and the average duration of pain was $43 \pm 49$ months. Test retest reliability of PSFS-T was found good level (ICC: 0.85 ). The relationship between PSFS-T and NDI was found moderate level $(p<0.05$, rho:-0.578). Furthermore, reading books/newspapers, cleaning and carrying heavy things were reported by Turkish neck patients as the first three activities which are the most problematic for their daily activities of life.

Conclusions: PSFS-T is a valid and reliable method of measuring outcome in patients with neck pain. Future studies should focus on the validity and reliability of PSFS-T in different populations.

\section{REFERENCE:}

[1] Blanpied PR, Gross AR, Elliott JM, Devaney LL, Clewley D, Walton DM, et al. Neck Pain: Revision 2017: Clinical Practice Guidelines Linked to the International Classification of Functioning, Disability and Health From the Orthopaedic Section of the American Physical Therapy Association. Journal of Orthopaedic \& Sports Physical Therapy 2017;47(7):A1-A83.

Disclosure of Interest: None declared

DOI: 10.1136/annrheumdis-2018-eular.4590

\section{SAT0723-HPR COMPARISON OF PHYSICAL ACTIVITY, FATIGUE, HEALTH-RELATED QUALITY OF LIFE, ANXIETY AND DEPRESSION BETWEEN ANKYLOSING SPONDYLITIS AND RHEUMATOID ARTHRITIS PATIENTS}

G.I. Kinikli ${ }^{1}$, M.E. Yayla ${ }^{2}$, A. Ates ${ }^{2}$, M. Turgay ${ }^{2}$, G. Kinikli ${ }^{2} .{ }^{1}$ Department of Physiotherapy and Rehabilitation, Faculty of Health Sciences, Hacettepe University; ${ }^{2}$ Department of Rheumatology, Ankara University, Faculty of Medicine, Ankara, Turkey

Background: Rheumatoid arthritis (RA) and ankylosing spondylitis (AS) are chronic progressive inflammatory diseases, leading to joint damage and reducing the physical fitness of patients. They are among the most common rheumatic diseases. Physical inactivity, fatigue, low health-related quality of life (HRQoL), higher anxiety and depression levels are common problems reported in patients both ankylosing spondylitis (AS) and rheumatoid arthritis (RA) although the clinical manifestations differ in many ways. These low outcomes have been found to be associated with functional limitations in both AS and RA serves as mediators in the link between disease activity and functional limitations in spite of NSAIDs and DMARDs therapies. Although many studies have assessed the outcomes of a single disease state, either RA or AS, few studies have focused on a direct comparison between those both diagnostic groups.
Objectives: The aim of this study to assess and compare physical activity, fatigue, HRQoL, anxiety and depression levels between AS and RA patients.

Methods: Twenty-six RA patients and 18 patients with AS were recruited from the outpatient clinic. Physical activity was assessed using the International Physical Activity Questionnaire-Short Form (IPAQ-SF), a validated instrument comprising of four items that estimates the levels of vigorous activity, moderate activity, walking and time spent sitting during the previous 7 days. The Fatigue Severity Scale (FSS) was used to measure the severity of fatigue. Disease-specific instruments to measure (HRQoL) in patients with RA and AS (RAQoL and ASQoL) were used. The Hospital Anxiety and Depression Scale (HADS) were used to assess anxiety and depression. The patient groups were compared using the Kruskal-Wallis test and the Chi-square test.

Results: Disease durations were similar between RA (mean age $=48.92 \pm 12.50$ years, disease duration $=10.81 \pm 7.68$ years) and AS (mean age $=43.44 \pm 12.36$ years, disease duration $=11.39 \pm 8.87$ years $)$ patients $(p=0.867)$. There was no statistically difference between FSS ( $R A=45.27 \pm 16.95 ; A S=41.00 \pm 12.95 ; p=0.173$ ) IPAQ-SF (RA=1289.65 $\pm 839.75 ; A S=2110.06 \pm 1210.86 ; \mathrm{p}=0.062)$ and HADS scores $(R A=18.31 \pm 2.93 ; A S=17.00 \pm 2.87 ; p=0.123)$ in both patient groups.

Conclusions: Our results support that physical inactivity due to impaired mobility as well as fatigue, anxiety/depression and low (HRQoL) are common and similar features of both RA and AS. In conclusion, management of disease activity with drug therapies should be targeted not only to improve physical function for RA and AS but also to improve physical activity levels, restore fatigue, anxiety and depression levels and preserve HRQoL.

\section{REFERENCES :}

[1] Lie E, Kristensen LE, Forsblad-d'Elia H, Zverkova-Sandström T, Askling J Jacobsson LT, et al. The effect of comedication with conventional synthetic disease modifying antirheumatic drugs on TNF inhibitor drug survival in patients with ankylosing spondylitis and undifferentiated spondyloarthritis: results from a nationwide prospective study. Ann Rheum Dis 2015;74:9708.

[2] lannone F, Lopalco G, Rigante D, Orlando I, Cantarini LG. Lapadulalmpact of obesity on the clinical outcome of rheumatologic patients in biotherapy Autoimmun Rev 2016;15:447-450

Disclosure of Interest: None declared DOI: 10.1136/annrheumdis-2018-eular.1149

\section{SAT0724-HPR TECHNOLOGICAL ASSISTED REHABILITATION FOLLOWING TOTAL KNEE JOINT REPLACEMENT. A RANDOMISED CONTROLLED NON-INFERIORITY TRIAL}

H.H. Andersen. University of Southern Denmark., Odense, Denmark

Background: Supervised rehabilitation after total knee arthroplasty (TKA) has been suggested effective for quicker recovery. The effect of Technological Assisted Rehabilitation (TAR) in the participant's home compared to supervised rehabilitation has been investigated in trials and results suggest it being equal to supervised rehabilitation on short time follow-up (6 weeks to 4 months). No studies have been found that evaluate the effect of TAR on follow-ups longer than 4 months.

Objectives: The aim of this study was to evaluate the effect of TAR compared to supervised rehabilitation (usual care) on participants with TKA after 6 and 12 months.

Methods: This was a single-blinded, randomised controlled, non-inferiority study 155 participants were randomised to either TAR (ICURA) or usual care. Intervention time was 6 weeks, follow-ups were after intervention, at 6 and 12 months. This study only concluded on 6 and 12 months. Primary outcome was $10 \mathrm{~m}$ walk test. Secondary outcomes were $2.45 \mathrm{~m}$ up and go, $30 \mathrm{~s}$. Sit to Stand, active knee flexion and extension and the KOOS questionnaire. All outcomes were measured at all time points by a blinded assessor. Non-inferiority margin was no statistical significant- and less than $10 \%$ between group difference at 6 and 12 months, estimated by a repeated measurement analysis, adjusted for relevant baseline variables.

Results: Overall, the groups did not differ at baseline. No statistical between group difference was detected after 6 and 12 months for primary and secondary outcomes. A power analysis suggested severe lack of power to detect a statistical between group difference, due to high numbers of participants lost to follow-up after 6 and 12 months. The between group difference at 6 and 12 months was less than $10 \%$ for all outcomes except KOOS Quality of Life at 6 months, were a difference of $12.2 \%$ was detected, in favour of ICURA

Conclusions: The results show that the effect of ICURA is equal to usual care after 6 and 12 months. Because lack of power after 6 and 12 months, the statistical significance should be interpreted with caution, but overall between group difference after 6 and 12 months was less than $10 \%$ for primary and secondary outcomes. 